\title{
Stop-and-go deglaciation
}

\author{
Past transitions from glacial to interglacial climates have not been smooth. It would be wise to prepare \\ for similarly sudden episodes of ice loss in future climate changes.
}

Only when climate records at centennial to millennial scales became available did the complexity of glacial terminations become apparent. Early low-resolution palaeoclimate reconstructions suggested a rapid and relentless meltdown. But at a closer look, an interhemispheric asynchrony emerged. Warming began in Antarctica around 18,000 years ago, which was interrupted by an abrupt reversal about 14,500 years ago. However, this southern cooling was countered by warming in the Northern Hemisphere until it too was interrupted by 1,000 years of cooling. Full interglacial conditions in both hemispheres were only reached after 11,700 years ago.

The long and complicated transition from full glacial conditions to early interglacial conditions (and beyond) are the subject of a Progress Article and a Review on pages 601 and 607 of this issue. Of particular interest is the transfer of water from vast continental ice sheets to the world's oceans, which led to a 120-metre rise in sea level.

Post-glacial sea-level rise followed an uneven trajectory. Against a background of a gradually rising waters, several distinct meltwater pulses, presumably from sudden partial ice-sheet collapses, pushed sea level up tens of metres within a few centuries. Synthesizing work on the past two glacial terminations, Carlson and Winsor (page 607) argue that rapid disintegration events are a hallmark of ice sheets that reach the ocean, whereas ice sheets that terminate on land have melted more steadily as more solar radiation reached them.

Törnqvist and Hijma (page 601) review studies of later, decimetre-scale rises that have become possible thanks to increasingly precise measurements. About 8,500 and 8,200 years ago, two rapid jumps in sea level have been linked to the final drainage of Lake Agassiz in northern North America, a lake of glacial meltwater on the margin of one of the largest ice sheets. The analysis suggests that such injections of fresh water into the ocean were not only the consequence of warming, but also a necessary condition for abrupt climate change associated with changes in the ocean circulation.

It is tempting, in the face of rising temperatures, to draw comparisons between the warming at the end of glacial periods and the projected melting of the remaining ice sheets on Greenland and Antarctica. The underlying causes of the deglaciation subtle changes in incoming solar radiation as the Earth's orbit around the Sun evolved were far slower than the changes in radiative forcing that are attributable to anthropogenic greenhouse gas emissions, and direct comparisons cannot be made. But in view of the climatic complications during the last deglaciation, the response to future climate change might be far from gradual.

\section{Feedback received}

\author{
In response to a survey conducted in June, 886 of our readers have told us what they think about \\ Nature Geoscience. We look forward to acting on the responses.
}

In a scientific journal's lifetime, perhaps the fifth year of publication marks the end of adolescence: any teething problems should have been solved; the scientific community will have formed an initial opinion of the new arrival; and the annual issuing of the journal impact factor will have become almost routine the third time around. At this transition into 'mature journalhood', we have surveyed the Nature Geoscience audience for their opinion of the journal.

We sent the survey to 27,137 people and received 1,002 responses between 6 and 22 June. 886 of the respondents stated that they have read content from the journal. We were pleased to hear that $82 \%$ of these readers rate the quality of Nature Geoscience as excellent or very good, with a further $14 \%$ saying the journal is good. We do, of course, realise that people who are willing to fill in a survey are more likely to be in favour of Nature Geoscience. Nevertheless, we are grateful for the broad support.
One surprise from the survey, from our point of view, was the widespread interest in peer review under double-blind conditions, where referees and authors are both anonymous. Three-quarters of our respondents either strongly or somewhat agreed that double-blind peer review is a good idea, whereas only $16 \%$ either strongly or somewhat disagreed. In view of this clear vote in favour of the process, we will be looking into ways of implementing a trial on an opt-in basis for authors.

We also note some ongoing uncertainties regarding the relationship between Nature Geoscience and Nature Climate Change. In a section for open comments, some respondents said they expected that Nature Geoscience would restrict itself to 'hard rock' science, now that Nature Climate Change has been established. As we have said before (Nature Geosci. 4, 129; 2011), this is not our plan. We aim to bring together research from all the Earth science disciplines, and we will continue to publish across subject areas, including those that are relevant to the Intergovernmental Panel for Climate Change.

As expected, the survey shows that researchers in each field tend to believe their own interest does not receive as much coverage as it deserves. But of all the broad topics, the planetary sciences were nominated most frequently by those outside the field as being under-represented. We have taken note, and will work to develop this area. Our planetary science editor Tamara Goldin, who joined us in January, will help with this initiative.

Finally, we are pleased that as many as $79 \%$ of our respondents mostly browse through the table of content rather than searching for specific papers. We set out to bring the broader picture to our readers (Nature Geosci. 1 563, 2008), by delivering a mix of content that will raise their interest in other fields. It seems that we are on track in this endeavour. 